\title{
Yes, I wear the Hijab. Yes, I am a Doctor.
}

No, I am not a patient.

Yes, I can hear you.

Yes, I can still use my stethoscope.

Yes, I can speak English.

Yes, I can speak Arabic - you're welcome.

I am honoured that you were hoping I would call your name in the waiting room. How can I help?

We are the same.

Yes, I have changed this hijab and covered it with a surgical balaclava, I am sterile.

No, I do not want to wear this sterile green drape over my head in theatre because you think I should.

Oh well. Here goes.

I'm from Sydney, thanks!

Yes, I am Australian. Accept me.

Yes, I am supposed to be in the drugs room. Here is my ID. Again.

No, I will not take my hijab off for the interview.

Please turn off the TV in the staff tearoom. It's really upsetting me. I don't want to hear what they are saying about me.

Yes, I am good at my job.

Thank you for your kind words.

I really can't come to the Pub. Can we please have a meeting elsewhere?

Thanks for the coffee, but I'm fasting.

No, I can't just eat because nobody is looking. I'm fasting.

Trust me, it's ok for this male doctor to examine you. I understand. I will stay here with you.

I am so happy!

I am so exhausted.

Please world, stop attacking me. I am trying to care for my patients.

The baby is born. I cry.

I will do obstetrics, of course.

I will do it.

\section{Rania Abdou}

Correspondence to Dr Rania Abdou, St George Hospital, Obstetrics and Gynaecology, Kogarah, New South Wales, Australia; Rania.Abdou@health.nsw.gov.au

Competing interests None declared.

Provenance and peer review Not commissioned; internally peer reviewed.

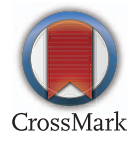

To cite Abdou R. Med Humanit 2017;43:e22.

Published Online First 22 February 2017

Med Humanit 2017;43:e22. doi:10.1136/medhum-2017-011219 